\title{
Darjeeling Zebrafish
}

National Cancer Institute

\section{Source}

National Cancer Institute. Darjeeling Zebrafish. NCI Thesaurus. Code C79969.

A wild-type zebrafish line, the stock of which was collected in Darjeeling, India in 1987.

This line has been maintained through inbreeding. It is used for gene mapping due to the presence of several polymorphic markers. 